\section{Forensic Neuropsychologist}

\author{
Robert L. Heilbronner \\ Chicago Neuropsychology Group, Chicago, IL, \\ USA
}

\section{Definition}

This refers to any neuropsychologist who offers opinions, with definable foreknowledge, about the psycholegal aspects of a legal case. A forensic neuropsychologist practices the application of neuropsychological assessment methods to the evaluation of criminal or civil litigants. The practice of forensic neuropsychology focuses the awareness of neuropsychologists on the critical areas of forensic practice that should be considered during each phase of a scientific neuropsychological examination/investigation. Forensic neuropsychologists provide important information to legal authorities (e.g., judges, attorneys) in cases where brain dysfunction is involved or alleged. They routinely rely upon standardized neuropsychological tests that measure various cognitive abilities and psychological states.

Forensic neuropsychologists fulfill three potential roles: (1) fact witness, (2) expert witness, and (3) litigation consultant. A fact witness is a neuropsychologist who is limited to providing testimony centered on the facts about the patient: they are usually considered an advocate of their patient/client. In contrast, an expert witness is a neuropsychologist who provides facts but also is afforded the opportunity to give opinions and report hearsay; they are an "advocate of the facts." A litigation consultant refers to a neuropsychologist who works "behind the scenes" to provide the attorney with education regarding basic neuropsychological terms and principles. A litigation consultation oftentimes reviews test data provided by another neuropsychologist and generates alternate theories for the neuropsychological facts and aids in the construction of questions to be utilized during the cross-examination of the opposing neuropsychologist.

\section{Cross-References}

\author{
Expert Witness \\ - Forensic Neuropsychology \\ - Forensic Psychology
}

\section{References and Readings}

Greiffenstein, M. F. (2009). Basics of forensic neuropsychology. In J. Morgan \& J. Ricker (Eds.), Textbook of clinical neuropsychology. New York: Taylor \& Francis.

Larrabee, G. J. (2005). A scientific approach to forensic neuropsychology. In G. Larrabee (Ed.), Forensic neuropsychology: A scientific approach. New York: Oxford University Press.

Sweet, J. J. (1999). Forensic neuropsychology: Fundamentals and practice. Lisse: Swets \& Zeitlinger. 